\title{
Willingness-to-Pay and Benefit-Cost Analysis of Botulinum Toxin for the Treatment of Rosacea in China: Findings from a Web-Based Survey
}

\author{
Xizhao Yang $\mathbb{D}^{1-3, *}$ \\ Yuyan Ouyang ${ }^{1-3, *}$ \\ Yuxuan Deng ${ }^{1,4}$ \\ Yi Xiao $\mathbb{D}^{\prime}$ \\ Yan Tang ${ }^{1-3}$ \\ Dan Jian ${ }^{1-3}$ \\ Ji Li ${ }^{1-3}$ \\ Hongfu Xie ${ }^{1-3}$ \\ Yingxue Huang ${ }^{1-3}$
}

'Department of Dermatology, Xiangya Hospital, Central South University, Changsha, People's Republic of China;

${ }^{2}$ National Clinical Research Center for Geriatric Disorders, Xiangya Hospital, Central South University, Changsha, People's Republic of China; ${ }^{3}$ Hunan Key Laboratory of Aging Biology, Changsha, People's Republic of China; ${ }^{4}$ Department of Dermatology and Allergy, and Christine Kühne-Center for Allergy Research and Education, University Hospital of Bonn, Bonn, D-53I27, Germany

*These authors contributed equally to this work

\begin{abstract}
Purpose: Botulinum toxin (BTX) is a new treatment approach primarily aimed at relieving flushing and erythema for rosacea, but it is expensive and lacks economic benefit evaluation studies.This study aimed to investigate willingness-to-pay (WTP) of BTX treatment and conduct benefit-cost analysis (BCA) to assess if BTX treatment for rosacea is recommendable from a viewpoint of economics in China.

Methods: WTP of BTX treatment in rosacea and information of sociodemographic and clinical characteristics were inquired via an online questionnaire among the Chinese rosacea patients. The WTP was inquired by photos of three cases with different severities of rosacea before and after BTX treatment. The benefit-cost ratio (BCR) was calculated by dividing WTP by cost. Factors associated with WTP were identified using logistic regression models. Results: The average costs of BTX treatment were USD410.09. The mean WTP for Case 1, Case 2, and Case 3 was USD295.53, 307.91, and 311.78, respectively ( $<<0.05$ for Case 1 vs Case 3). $44.31 \%$ to $47.52 \%$ of Chinese rosacea patients were willing to pay for the BTX treatment. The BCRs were $0.72,0.75$, and 0.76 for Case 1, Case 2, and Case 3, respectively. A positive correlation between WTP and visiting frequency in the past year $(\mathrm{OR}=1.181-1.200, \mathrm{p}=0.015-0.032$, for Cases 1 and 2 ) or Dermatology Life Quality Index (DLQI) score ( $\mathrm{OR}=2.022-2.266$, all $\mathrm{p}<0.01)$ was observed, but duration $(\mathrm{OR}=0.521-0.564$, $\mathrm{p}<0.05$, for Cases 1 and 2) of rosacea was negatively correlated with WTP.
\end{abstract}

Conclusion: For rosacea patients with poor quality of life, and those with high visiting frequency, BTX should be regarded as a recommendable new treatment in China.

Keywords: rosacea, botulinum toxin, willingness-to-pay, benefit-cost analysis, quality of life

\section{Introduction}

Rosacea is a chronic inflammatory skin disease that occurs in the middle of the face. Manifestations include recurrent flushing, persistent facial erythema, papules, pustules, and telangiectasia. Phymatous changes (hypertrophy of the sebaceous glands and fibrosis) and ocular discomfort can also occur. ${ }^{1}$ In addition, rosacea patients can be accompanied by dryness, burning, stinging and other discomfort on the face. ${ }^{2}$ Globally, about $5.46 \%$ of the adult general population is affected by rosacea. ${ }^{3}$ The prevalence of rosacea across populations has been reported $3.48 \%$ in China. ${ }^{4}$

The pathogenesis of rosacea is not fully understood but involves the complex interplay of genetic factors, immune dysregulation, neurovascular dysregulation,
Correspondence: Yingxue Huang Department of Dermatology, Xiangya Hospital, Central South University, 87 Xiangya Road, Changsha, Hunan, 410008, People's Republic of China Tel +86 I86 27556448

Email huangyingxue1987@163.com 
presence of microorganisms, and environmental factors. ${ }^{5}$ Treatment of rosacea depends on the severity and phenotype presentation and may include topical therapies, oral therapies, laser- and light-based therapies, injection therapies, skin care, and lifestyle management. ${ }^{6,7}$ Currently, treatment approved by the Food and Drug Administration (FDA) mainly targets papules and pustules, but the difficulties in the clinical treatment are the persistent facial erythema and recurrent flushing. Some adrenergic agonists (brimonidine, oxymetazoline, etc.) showed effectiveness but can only maintain a short time of relief. ${ }^{8,9}$ The annoying symptoms of rosacea have been paid more and more attention by the patients because of its disfiguring features, and many dermatologists are committed to seeking optimized treatments.

Botulinum toxin (BTX) is a neurotoxin derived from the Clostridium botulinum bacterium that inhibits the release of acetylcholine at the neuromuscular junction level. ${ }^{10}$ Besides its effects on muscles, the blockade of acetylcholine release from peripheral autonomic nerves of the cutaneous vasodilatory system could inhibit the release of inflammatory mediators such as substance $\mathrm{P}$ and calcitonin gene-related peptide (CGRP), which have a relevant effect on vasodilation ${ }^{11}$ and also reduce skin inflammation by directly inhibiting mast cell degranulation. ${ }^{12}$ Based on the effects on blood vessels and inflammation, BTX injection has been progressively applied on rosacea patients with refractory erythema and flushing. ${ }^{13-15}$ However, the cost of this treatment is far more than traditional drug therapy; thus, it is very necessary to evaluate the benefitof-cost from a viewpoint of economics.

The willingness-to-pay (WTP) method utilizes survey questions to ask patients how much they would be willing to pay to cure or relieve a particular disease. To understand whether a patient's WTP for a particular treatment exceeds its cost, a benefit-cost analysis (BCA) is needed. ${ }^{16}$ There are few studies on the benefit and cost of topical and oral drug therapy for rosacea. ${ }^{17,18}$ But studies on the benefits and costs of a novel treatment for rosacea have been lacking, especially in China. We conducted this study to assess whether BTX therapy, a novel and expensive treatment, is acceptable among rosacea patients in the Chinese population.

\section{Methods}

\section{Study Design and Participants}

The web-based, cross-sectional study was conducted using standardized questionnaires sent by "WeChat" (January 2020 to April 2020), the most popular mobile chatting application in China, to eligible respondents. Eligible participants were Chinese at least 18 years of age and from the Rosacea Database of Xiangya Hospital, Central South University, who had registered ahead of the survey. All the patients registered in the Database have been diagnosed by two dermatologists separately and met the diagnostic criteria of rosacea based on the National Rosacea Society Expert Committee. Each participant was allowed to submit a questionnaire once by the IP address in order to avoid repeated submissions. Participants were required to be able to read and understand Chinese.

\section{Benefits: WTP}

WTP approximated benefits in our study via the contingent valuation method. ${ }^{19}$ The participants received education about the process and adverse effects of BTX treatment. Three typical cases demonstrating average effects of one- or three- or five-time use of BTX treatment in Chinese rosacea patients with different severity grading were presented to the participants (Figure 1).

We use the same binary questions to obtain WTP:

Would you be willing to pay 3000 RMB (USD429.89) per time for this new treatment with minimal side effects to achieve the effects as shown in contrast figure? (This new treatment requires one or three or five-time visits in the three cases, respectively.)

The answer to this question is "yes or no". If you choose "yes", then stop this question. If you choose "no", then answer the next question: "How much would you be willing to pay per time at most for this treatment?" The options of WTP consisted of four discrete amounts of monetary value as follows: Chinese yuan (CNY) 2700, 2500, 2000, and 1000 .

\section{Aggregated Costs}

We estimated costs from the patient perspective. ${ }^{16}$ Direct medical costs (physician visit fees, BTX treatment fees, and post-treatment complementary costs), direct nonmedical costs (travel costs), and indirect costs (time off from work to visit physician) were considered (Table 1). Since there was no standard pricing for BTX treatment in China, the price per BTX treatment was estimated using the mean cost in three Chinese tertiary hospitals (Xiangya Hospital; Xiangya Second Hospital; and The Third Xiangya Hospital, Central South University). Physicians' professional fees and indirect costs in terms of time loss were 


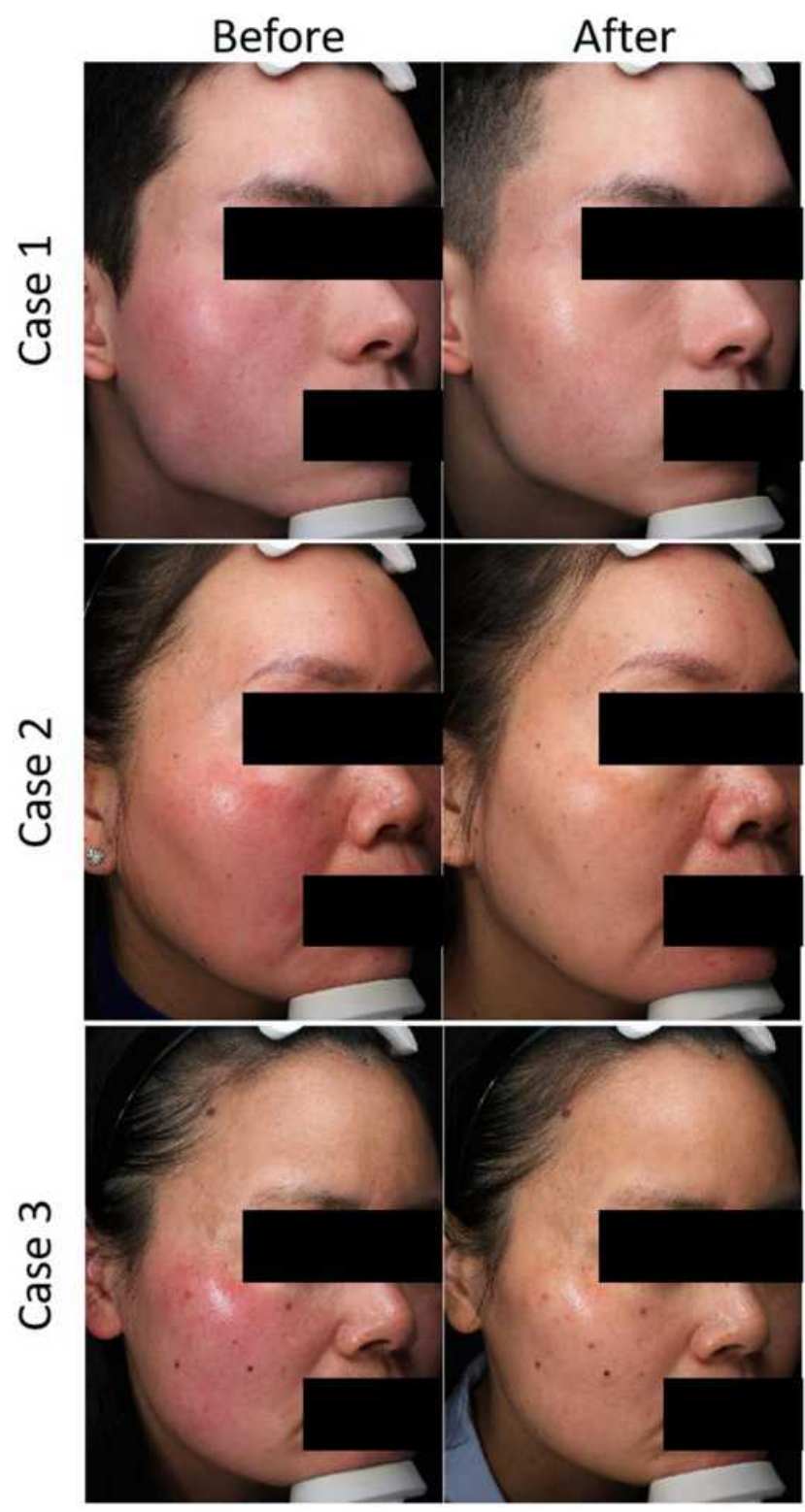

Figure I Contrast figures of three cases treated with BTX.

estimated according to the data from the 2019 Yearbook of Health Statistics of China and the 2019 Yearbook of labor Statistics of China. ${ }^{20,21}$ All costs in this study are expressed in USD with an exchange rate of USD $1=$ CNY6.9785 (2019).

\section{BCA}

The BCA model was based on the benefit-cost ratio (BCR), calculated as the average WTP divided by the total cost for BTX treatment as previously described. ${ }^{16}$ If the benefits outweighed the costs (ie, BCR $>1$ ), the BTX treatment was considered worth providing.

\section{Other Variables}

Dermatology Life Quality Index (DLQI), ${ }^{22}$ a widely used tool to evaluate skin disease patients' quality of life (QoL), was used to examine the correlation between QoL and WTP. Information regarding age, gender, residence, income, education level, marital status, knowledge of rosacea, rosacea-related symptoms, duration and treatment history of disease, and disturbed degree of flushing were also collected.

\section{Statistical Analyses}

Descriptive statistics were reported for sociodemographic and clinical characteristics, average WTP for each case and other survey metrics for each participant. The MannWhitney $U$-tests (binary variables) or Kruskal-Wallis tests (multi-categorical variables) were used to compare the WTP of patients with different variables.

The Friedman test was used to compare the mean WTP among the three cases. Logistic regression models were used to estimate the associations of WTP with the characteristics of the participants. SPSS 22.0 was used for statistical analysis. $\mathrm{P}<0.05$ was considered statistically significant.

\section{Ethics Statement}

Electronic informed consent was obtained from all participants before the investigation. Before the pictures of the three cases were used in the questionnaires and articles, written informed consent has been obtained from the patients. This study was conducted according to the guidelines laid down in the Declaration of Helsinki. All procedures involving patients were approved by the Institutional Research Ethics Board of Xiangya Hospital, Central South University (Changsha, China).

\section{Results}

\section{Sociodemographic and Clinical Characteristics}

The response rate was $98.54 \%$, and a total of 410 anonymous participants were recruited of which 404 were analyzed. The other six participants were excluded because they were younger than 18 years old. Among 404 participants, 34 were males and 370 were females. The average age of the population is $28.55 \pm 8.38$. Sociodemographic and clinical characteristics of the participants and the mean WTP are shown in Table 2. Except for the income, different sociodemographic characteristics 
Table I Aggregated Costs of BTX Treatment

\begin{tabular}{|l|c|c|c|c|}
\hline Costs & Hospitall (USD) & Hospital2 (USD) & Hospital3 (USD) & Average (USD) \\
\hline Direct costs & & & & 4.00 \\
Physician visit & 4.16 & 5.25 & 372.57 & 3.47 \\
BTX treatment & 358.24 & 429.89 & 3.00 & 3.00 \\
Post-treatment & 2.00 & 4.00 & 2.00 & 2.00 \\
\hline $\begin{array}{l}\text { Direct nonmedical costs } \\
\text { In-city transportation }\end{array}$ & 2.00 & 2.00 & & 13.73 \\
\hline Indirect costs \\
Time off from work
\end{tabular}

including gender, age, residence, etc., were not statistically different in WTP. For the clinical characteristics of the participants, there was no significant difference in WTP among the different affected locations or symptoms. However, patients with better knowledge of rosacea, shorter duration of rosacea, more frequent visits, and higher DLQI score had higher WTP.

\section{WTP}

The mean WTP for Case 1, Case 2, and Case 3 was USD295.53, 307.91, and 311.78, respectively (Figure $2 \mathrm{~A})$. There were statistically significant differences in WTP among Case 1 vs Case 3. In Case 1, 179 (44.31\%) patients were willing to pay USD429.89 covering the cost. In Cases 2 and 3, there were 184 (45.54\%) and 192 (47.52\%) patients, respectively.

Factors for WTP were analyzed using logistic regression models. As shown in Table 3, the family income was positively correlated with WTP in all cases $(\mathrm{OR}=1.347-1.409, \mathrm{p}<0.001)$. In case 3 , patients who do not know about rosacea were less willing to pay the costs than those who know it a lot $(\mathrm{OR}=0.568, \mathrm{p}=0.019)$. The duration of rosacea was negatively correlated with WTP in Case 1 and Case 2 (OR=0.521-0.564, $\mathrm{p}<0.05)$. A statistically significant and positive correlation between WTP and visiting frequency in the past year was observed for Case 1 and Case 2 after adjustments for demographic characteristics $(\mathrm{OR}=1.181-1.200, \mathrm{p}=0.015-0.032)$.

\section{DLQI}

The mean DLQI score in rosacea patients was $11.14 \pm 7.92$ (range from 0 to 30), indicating a large influence of rosacea on QoL. $45.30 \%$ of all participants had a total DLQI score greater than or equal to 11 (Table 2), indicating severe impaired QoL, ${ }^{23}$ and the median WTP of them is greater than the cost (Figure 2B). DLQI score was positively correlated with WTP in all cases with the highest OR value among the identified independent factors $(\mathrm{OR}=2.022-2.266$, all $\mathrm{p}<0.01)$ (Table 3).

\section{BCR}

As shown in Table 4, all of three cases had $\mathrm{BCR}<1$, indicating that the expected benefits are below the aggregated costs for the BTX treatments. Because the denominators of the BCRs were the same across the participants, the influence factors for the BCRs were equivalent to those for WTP (Table 3).

\section{Discussion}

BTX is a new treatment with great potential for the persistent erythema and recurrent flushing of rosacea, but it is so expensive that it is hard to be widely accepted economically. We conducted a web-based investigation about the WTP of treatment with BTX for rosacea and found more than $40 \%$ of patients were willing to pay the corresponding amount of cost. The BCA based on the WTP survey in this study is of important reference significance for the promotion of this treatment.

In the present study, the elicited WTP values are valid because WTP were positively related to income, in accordance with the economic common sense. The WTP increased with the disease severity, which was supported by a significantly higher WTP of Case 3 than that of Case 1, as a much larger visualized effect of BTX in severe Case 3. Since patients' self-assessment of severity is subjective to a certain extent, we did not collect data on participants' severity in this web-based study. Instead, we asked the times of hospital visits in the past year to know about the flare-ups of rosacea. We found that patients with more 
Table 2 Sociodemographic and Clinical Characteristics of the Participants

\begin{tabular}{|c|c|c|c|c|}
\hline \multirow{2}{*}{ Characteristics } & \multirow[t]{2}{*}{$\mathbf{N}(\%)$} & \multicolumn{3}{|c|}{ WTP (USD) } \\
\hline & & Case I & Case 2 & Case 3 \\
\hline \multicolumn{5}{|l|}{ Gender } \\
\hline Male & $34(8.42)$ & 299.24 & 292.92 & 286.59 \\
\hline Female & $370(91.58)$ & 295.19 & 309.29 & 314.09 \\
\hline \multicolumn{5}{|l|}{ Age, years } \\
\hline $18-20$ & $54(13.37)$ & 311.80 & 310.48 & 309.15 \\
\hline $21-30$ & $215(53.22)$ & 290.73 & 306.66 & 308.99 \\
\hline $31-40$ & $92(22.77)$ & 305.28 & 316.97 & 326.62 \\
\hline$>40$ & $43(10.64)$ & 278.26 & 291.59 & 297.26 \\
\hline \multicolumn{5}{|l|}{ Residence } \\
\hline Urban & $361(89.36)$ & 292.95 & 305.61 & 310.25 \\
\hline Village & $43(10.64)$ & 317.25 & 327.25 & 324.59 \\
\hline \multicolumn{5}{|l|}{ Education level } \\
\hline Low (primary school, secondary school) & $69(17.08)$ & 280.36 & 286.59 & 292.62 \\
\hline Medium (college/university) & $299(74.01)$ & 297.47 & 310.37 & 313.72 \\
\hline High (postgraduate) & $36(8.91)$ & 308.49 & 328.39 & 332.37 \\
\hline \multicolumn{5}{|l|}{ Marital status } \\
\hline Single & $172(42.58)$ & 288.01 & 297.09 & 302.09 \\
\hline In a stable relationship & $72(17.82)$ & 286.59 & 307.49 & 305.50 \\
\hline Married & $160(39.60)$ & 307.64 & 319.73 & 325.02 \\
\hline \multicolumn{5}{|l|}{ Monthly family income, USD* } \\
\hline No stable income & $40(9.90)$ & 261.52 & 279.43 & 285.52 \\
\hline$<603$ & $82(20.30)$ & 286.07 & 302.15 & 300.05 \\
\hline $603-1189$ & $92(22.77)$ & 261.67 & 279.12 & 285.66 \\
\hline $1190-2378$ & $114(28.22)$ & 307.34 & 311.73 & 311.73 \\
\hline$>2378$ & $76(18.8 \mid)$ & 346.93 & 358.24 & 369.93 \\
\hline \multicolumn{5}{|l|}{ Knowledge of rosacea* } \\
\hline You have it, and you know it & $266(65.84)$ & 306.90 & 320.21 & 329.48 \\
\hline You have it, but you do not know about it & $138(34.16)$ & 273.61 & 284.21 & 277.66 \\
\hline Duration of rosacea & & \# & & \\
\hline Within a year & $85(21.04)$ & 325.37 & 324.02 & 322.84 \\
\hline More than one year & $319(78.96)$ & 287.58 & 303.62 & 308.83 \\
\hline \multicolumn{5}{|l|}{ Location of lesion } \\
\hline Cheek as main part & $351(86.88)$ & 298.52 & 311.95 & 316.40 \\
\hline Non-cheek as main part & $53(13.12)$ & 275.78 & 281.19 & 281.19 \\
\hline \multicolumn{5}{|l|}{ The most concerned problem } \\
\hline Facial flushing & $156(38.61)$ & 304.69 & 315.44 & 316.45 \\
\hline Erythema/teleangiectasia & $79(19.56)$ & 302.92 & 332.30 & 326.50 \\
\hline Papules/pustules & II $6(28.7 \mathrm{I})$ & 287.83 & 289.68 & 296.48 \\
\hline Phymatous & $12(2.97)$ & 262.71 & 262.71 & 286.59 \\
\hline Others & $4 I(10.15)$ & 277.86 & 297.08 & 316.30 \\
\hline \multicolumn{5}{|l|}{ Disturbed degree of flushing } \\
\hline $0-3$ & 71 (II.57) & 291.04 & 311.62 & 310.21 \\
\hline $4-6$ & $123(30.45)$ & 294.75 & 313.97 & 317.58 \\
\hline $7-10$ & $210(51.98)$ & 297.51 & 303.11 & 308.91 \\
\hline
\end{tabular}

(Continued) 
Table 2 (Continued).

\begin{tabular}{|c|c|c|c|c|}
\hline \multirow[t]{2}{*}{ Characteristics } & \multirow[t]{2}{*}{$\mathbf{N}(\%)$} & \multicolumn{3}{|c|}{ WTP (USD) } \\
\hline & & Case I & Case 2 & Case 3 \\
\hline \multicolumn{5}{|l|}{ Visiting frequency in the past year* } \\
\hline 0 & $55(13.62)$ & 276.17 & 289.72 & 291.02 \\
\hline 1 & $76(\mid 8.8 I)$ & 264.91 & 284.14 & 297.34 \\
\hline 2 & $80(19.80)$ & 282.47 & 294.12 & 298.60 \\
\hline 3 & 65 (16.09) & 288.80 & 284.39 & 284.17 \\
\hline$\geq 4$ & $128(31.68)$ & 333.61 & $350.4 I$ & 351.53 \\
\hline \multicolumn{5}{|l|}{ DLQI score (quality of life effect)* } \\
\hline $0-10$ (moderate or below effect) & $221(54.70)$ & 269.87 & 286.85 & 289.84 \\
\hline II-30 (severe or above effect) & I83 (45.30) & 326.53 & 333.34 & 338.28 \\
\hline
\end{tabular}

Notes: *The difference of WTP was statistically significant in all three cases. ${ }^{\#}$ The difference of WTP was statistically significant in Case I.

visiting frequency in the past year were more likely to pay for BTX therapy. The times of hospital visits also indirectly reflect the severity of the disease, further supporting its association with the WTP.

Skin disease can have an impact on QoL that goes beyond what is measured by a disease severity score, and as such, patients' subjective complaint of their skin disease is crucial for evaluating QoL. DLQI is recognized as a common scale for evaluating the quality of life of dermatosis patients. ${ }^{22,23}$ In the current study, the mean DLQI total score of the participants was 11.14, similar to that in the previous literature, ${ }^{24,25}$ indicating a large influence on QoL. The WTP method has also been used as a valuation measure for healthcare and health-related quality of life (HRQoL) by inquiring the substantial amount of money patients are willing to pay to reduce their symptoms. A higher WTP often indicates a worse HRQoL. ${ }^{26}$ In our study, the WTP was specific for BTX treatment, rather than the total WTP for a complete cure of the disease, but it can represent the patient's treatment desire and urgency as well and reflect the impairment of QoL. Based on our results, DLQI score is positively related to WTP with the highest OR value, which is consistent with previous studies on the relationship between WTP and QoL in rosacea. ${ }^{27,28}$ In addition, patients with a long course of disease were less willing to pay the costs, consistent with the viewpoint that the longer the disease course of rosacea, the lesser the impairment of QoL. ${ }^{27}$ In order to better manage patients and increase satisfaction, dermatologists should pay more attention to the complaint of the patients and notice the low QoL of the disease.

By calculating whether the expected WTP value can be sufficient to cover the expected costs, BCA can help to make decisions and subdivide patients' demands. For BCA in this study, BCR was less than 1 in all three cases, but there are still $43.81 \%$ to $47.03 \%$ of Chinese rosacea patients were willing to
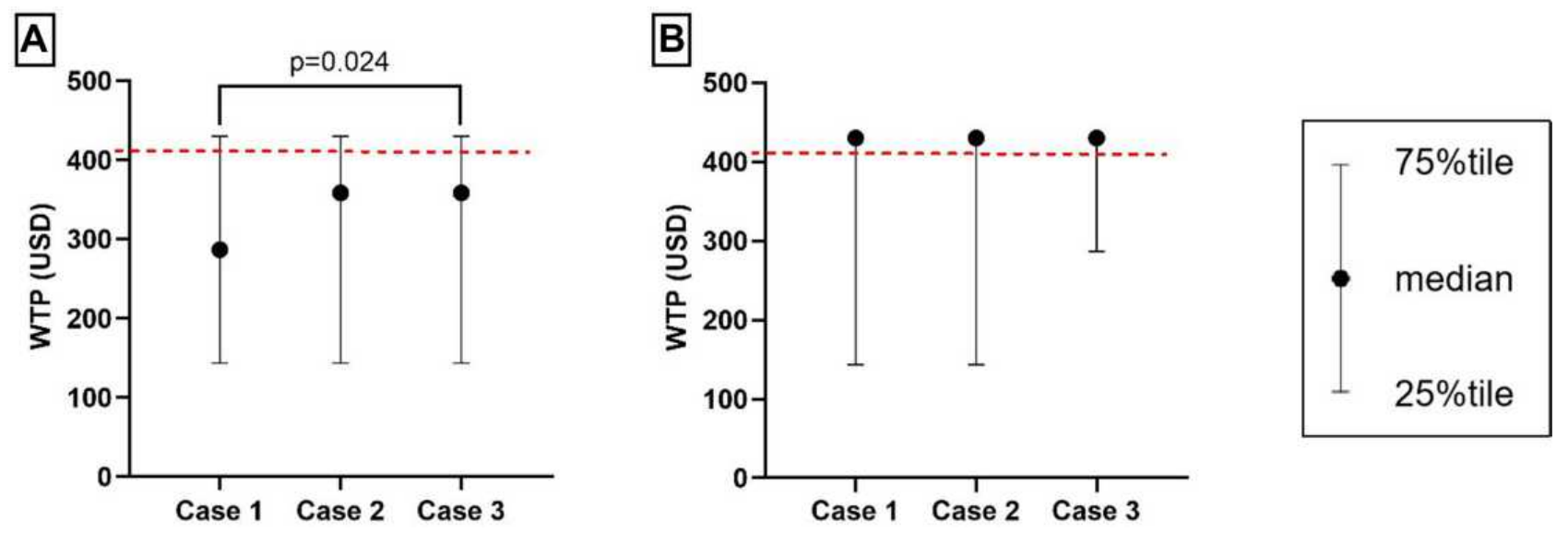

Figure 2 WTP for different cases of BTX treatment $(\mathbf{A})$ is for all participants; $(\mathbf{B})$ is for participants with a total DLQI score greater than or equal to II). Red line means the costs (USD410.09). 
Table 3 Relativity Between Patients' Characteristics and WTP: Logistic Regression Models

\begin{tabular}{|c|c|c|c|c|c|c|}
\hline \multirow[t]{2}{*}{ Characteristics } & \multicolumn{2}{|l|}{ Case I } & \multicolumn{2}{|l|}{ Case 2} & \multicolumn{2}{|l|}{ Case 3} \\
\hline & OR $(95 \% \mathrm{Cl})$ & p-value & OR $(95 \% \mathrm{Cl})$ & p-value & OR $(95 \% \mathrm{Cl})$ & p-value \\
\hline Monthly family income & $1.352(1.132-1.615)$ & 0.001 & $1.347(1.130-1.607)$ & 0.001 & $1.409(1.182-1.679)$ & 0.000 \\
\hline $\begin{array}{l}\text { Knowledge of rosacea } \\
\text { You have it, and you know it (ref) } \\
\text { You have it, but you do not know about it }\end{array}$ & l & l & l & I & $0.568(0.354-0.910)$ & 0.019 \\
\hline $\begin{array}{l}\text { Duration of rosacea } \\
\text { Within a year (ref) } \\
\text { More than one year }\end{array}$ & $0.521(0.307-0.882)$ & 0.015 & $0.564(0.334-0.952)$ & 0.032 & l & I \\
\hline Visiting frequency in the past year & $1.181(1.001-1.395)$ & 0.049 & $1.200(1.018-1.415)$ & 0.030 & l & l \\
\hline $\begin{array}{l}\text { DLQI score } \\
\text { 0-10 (ref) } \\
\text { II-30 }\end{array}$ & $2.206(1.404-3.466)$ & 0.001 & $2.022(1.291-3.167)$ & 0.002 & $2.266(1.470-3.491)$ & 0.000 \\
\hline
\end{tabular}

Table 4 Benefit-Cost Ratios

\begin{tabular}{|l|c|c|c|}
\hline Case & WTP (USD) & Costs (USD) & BCR \\
\hline 1 & 295.53 & 410.09 & 0.72 \\
2 & 307.91 & 410.09 & 0.75 \\
3 & 311.78 & 410.09 & 0.76 \\
\hline
\end{tabular}

pay for the BTX treatment. Although traditional treatments are effective for most patients, oral and topical drugs may cause side effects, ${ }^{29,30}$ and the patient's daily medication compliance is not guaranteed. Most importantly, very few drugs can currently control facial flushing, but it is precisely the feeling of flushing and the accompanying burning, stinging and other symptoms that affected QoL most. ${ }^{31,32}$ As a relatively new treatment method, BTX injections show its advantages on relieving the paroxysmal flushing and persistent erythema of rosacea. In a retrospective study, 16 patients who suffered from facial erythema and flushing refractory to conventional treatments displayed significantly improved Clinicians Erythema Assessment (CEA) and Patients self-assessment (PSA) scores after twice treatments with topical application of $100 \mathrm{U}$ of BTX. DLQI scores were also significantly improved, and the effect persisted during a 6-month follow-up. ${ }^{13}$ In a pilot study of a randomized controlled trial with 24 patients, similar effects were also observed. ${ }^{14}$ Based on our results, symptoms that rosacea patients most concerned were facial flushing or erythema/telangiectasia, accounting for $57.92 \%$ of participants, and $51.98 \%$ of the participants reported a score of 7 or more (a VAS scale of 10 score) for the disturbed degree of flushing. Therefore, even the percent of patients willing to pay was only just above $40 \%$, BTX was still a selective choice for those felt suffered. We recommend BTX therapy for patients with higherincome families and unresponsive to routine treatments, especially for patients with poor quality of life, and urgent desire to solve the problem of facial flushing or erythema.

In addition, we had another interesting finding compared with patients who do not know about rosacea, who know much about rosacea and who were more willing to pay for costs. It may be explained that for patients who do not understand the characteristics of recurrence and aggravation of rosacea disease, spending so many money for BTX injection was not worthy. Therefore, health education specific for rosacea is so important and necessary that the educated patients may have more opportunities to accept better treatments.

As with any modeling-based analysis, the limitations of this study are inherent. First, the selected sample cannot represent the whole demographics of Chinese rosacea patients. This sample was younger and more educated compared to the general population. However, the data are still statistically significantly different after adjustments to demographic characteristics. In addition, as a web-based survey, the condition of rosacea was self-reported by participants so is likely to focus on their own perception of disease, rather than clinical severity. However, we provided photographs of varying degrees of severity to assess the association between WTP and the disease severity.

\section{Conclusion}

The benefits of BTX treatment have not generally exceeded their aggregated costs across the three cases, but more than $40 \%$ of patients were willing to pay the corresponding amount of cost. For rosacea patients with poor quality of life, and those 
with relatively high income, BTX should be regarded as a recommendable new treatment in China.

\section{Acknowledgment}

This work was supported by the National Natural Science Foundation of China (No.81502750). Co-first authors: Xizhao Yang and Yuyan Ouyang.

\section{Disclosure}

The authors have no conflicts of interest to declare.

\section{References}

1. van Zuuren EJ. Rosacea. N Engl J Med. 2017;377(18):1754-1764. doi:10.1056/NEJMcp1506630

2. Buddenkotte J, Steinhoff M. Recent advances in understanding and managing rosacea. F1000Res. 2018;7. doi:10.12688/f1000 research.16537.1

3. Gether L, Overgaard LK, Egeberg A, Thyssen JP. Incidence and prevalence of rosacea: a systematic review and meta-analysis. $\mathrm{Br}$ $J$ Dermatol. 2018;179(2):282-289. doi:10.1111/bjd.16481

4. Li J, Wang B, Deng Y, et al. Epidemiological features of rosacea in Changsha, China: a population-based, cross-sectional study. J Dermatol. 2020;47(5):497-502. doi:10.1111/1346-8138.15301

5. Ahn CS, Huang WW. Rosacea pathogenesis. Dermatol Clin. 2018;36 (2):81-86. doi:10.1016/j.det.2017.11.001

6. Zhang H, Tang K, Wang Y, Fang R, Sun Q. Rosacea treatment: review and update. Dermatol Ther (Heidelb). 2021;11(1):13-24. doi:10.1007/s13555-020-00461-0

7. Thiboutot D, Anderson R, Cook-Bolden F, et al. Standard management options for rosacea: the 2019 update by the National Rosacea Society Expert Committee. J Am Acad Dermatol. 2020;82 (6):1501-1510. doi:10.1016/j.jaad.2020.01.077

8. Shanler SD, Ondo AL. Successful treatment of the erythema and flushing of rosacea using a topically applied selective alpha1-adrenergic receptor agonist, oxymetazoline. Arch Dermatol. 2007;143(11):1369-1371. doi:10.1001/archderm.143.11.1369

9. Fowler J, Jackson M, Moore A, et al. Efficacy and safety of once-daily topical brimonidine tartrate gel $0.5 \%$ for the treatment of moderate to severe facial erythema of rosacea: results of two randomized, double-blind, and vehicle-controlled pivotal studies. J Drugs Dermatol. 2013;12(6):650-656.

10. França K, Kumar A, Fioranelli M, Lotti T, Tirant M, Roccia MG. The history of Botulinum toxin: from poison to beauty. Wien Med Wochenschr. 2017;167(Suppl 1):46-48. doi:10.1007/s10354-017-0553-7

11. Scala J, Vojvodic A, Vojvodic P, et al. Botulin toxin use in rosacea and facial flushing treatment. Open Access Maced J Med Sci. 2019;7 (18):2985-2987. doi:10.3889/oamjms.2019.784

12. Choi JE, Werbel T, Wang Z, Wu CC, Yaksh TL, Di Nardo A. Botulinum toxin blocks mast cells and prevents rosacea like inflammation. J Dermatol Sci. 2019;93(1):58-64. doi:10.1016/j.jdermsci.2018.12.004

13. Friedman O, Koren A, Niv R, Mehrabi JN, Artzi O. The toxic edge a novel treatment for refractory erythema and flushing of rosacea. Lasers Surg Med. 2019;51(4):325-331. doi:10.1002/1sm.23023

14. Kim MJ, Kim JH, Cheon HI, et al. Assessment of skin physiology change and safety after intradermal injections with botulinum toxin: a randomized, double-blind, placebo-controlled, split-face pilot study in rosacea patients with facial erythema. Dermatol Surg. 2019;45 (9):1155-1162. doi:10.1097/dss.0000000000001819
15. Al-Niaimi F, Glagoleva E, Araviiskaia E. Pulsed dye laser followed by intradermal botulinum toxin type - a in the treatment of rosaceaassociated erythema and flushing. Dermatol Ther. 2020;33(6): e13976. doi: $10.1111 /$ dth. 13976

16. Xiao Y, Chen L, Jing D, et al. Willingness-to-pay and benefit-cost analysis of chemical peels for acne treatment in China. Patient Prefer Adherence. 2019;13:363-370. doi:10.2147/ppa.S194615

17. Thomas K, Yelverton CB, Yentzer BA, Balkrishnan R, Fleischer AB, Feldman SR. The cost-effectiveness of rosacea treatments. J Dermatolog Treat. 2009;20(2):72-75. doi:10.1080/09546630802314662

18. Taieb A, Stein Gold L, Feldman SR, Dansk V, Bertranou E. Costeffectiveness of ivermectin $1 \%$ cream in adults with papulopustular rosacea in the United States. J Manag Care Spec Pharm. 2016;22 (6):654-665. doi:10.18553/jmcp.2016.15210

19. Mitchell RC, Carson RT. Using Surveys to Value Public Goods: The Contingent Valuation Method. Washington, DC: Resources for the Future; 2013.

20. China. N.B.o.S.o.t.P.s.R.o. China Labour Statistical Yearbook 2019. Beijing: China Statistics Press; 2019.

21. China. N.H.C.o.t.P.s.R.o. 2019 Yearbook of Health Statistics of China. Beijing: Beijing Union Medical University Press; 2019.

22. Finlay AY, Khan GK. Dermatology Life Quality Index (DLQI) - a simple practical measure for routine clinical use. Clin Exp Dermatol. 1994;19 (3):210-216. doi:10.1111/j.1365-2230.1994.tb01167.x

23. Basra MK, Fenech R, Gatt RM, Salek MS, Finlay AY. The Dermatology Life Quality Index 1994-2007: a comprehensive review of validation data and clinical results. $\mathrm{Br} J$ Dermatol. 2008;159 (5):997-1035. doi:10.1111/j.1365-2133.2008.08832.x

24. Lewis V, Finlay AY. 10 years experience of the Dermatology Life Quality Index (DLQI). J Investig Dermatol Symp Proc. 2004;9 (2):169-180. doi:10.1111/j.1087-0024.2004.09113.x

25. Wu Y, Fu C, Zhang W, Li C, Zhang J. The Dermatology Life Quality Index (DLQI) and the hospital anxiety and depression (HADS) in Chinese rosacea patients. Psychol Health Med. 2018;23(4):369-374. doi:10.1080/13548506.2017.1361540

26. VanBeek MJ. Integrating patient preferences with health utilities: a variation on health-related quality of life. Arch Dermatol. 2008;144(8):1037-1041. doi:10.1001/archderm.144.8.1037

27. Beikert FC, Langenbruch AK, Radtke MA, Augustin M. Willingness to pay and quality of life in patients with rosacea. J Eur Acad Dermatol Venereol. 2013;27(6):734-738. doi:10.1111/j.1468-3083.2012.04549.x

28. Tan J, Steinhoff M, Bewley A, Gieler U, Rives V. Characterizing high-burden rosacea subjects: a multivariate risk factor analysis from a global survey. $J$ Dermatolog Treat. 2020;31(2):168-174. doi:10.1080/09546634.2019.1623368

29. Akhyani M, Ehsani AH, Ghiasi M, Jafari AK. Comparison of efficacy of azithromycin vs. doxycycline in the treatment of rosacea: a randomized open clinical trial. Int $J$ Dermatol. 2008;47 (3):284-288. doi:10.1111/j.1365-4632.2008.03445.x

30. Williamson T, Cheng WY, McCormick N, Vekeman F. Patient preferences and therapeutic satisfaction with topical agents for rosacea: a survey-based study. Am Health Drug Benefits. 2018;11(2):97-106.

31. Zeichner JA, Eichenfield LF, Feldman SR, Kasteler JS, Ferrusi IL. Quality of life in individuals with erythematotelangiectatic and papulopustular rosacea: findings from a web-based survey. J Clin Aesthet Dermatol. 2018;11(2):47-52.

32. Qi S, Zhixiang Z, Hongfu X, Ji L, Ben W. Analysis of clinical features of intermittent flushing in patients with rosacea and its impact on quality of life. Chine J Dermatol. 2020;53(5):340-344. doi:10.35541/cjd.20191198 


\section{Publish your work in this journal}

Patient Preference and Adherence is an international, peer-reviewed open access journal that focusing on the growing importance of patient preference and adherence throughout the therapeutic continuum. Patient satisfaction, acceptability, quality of life, compliance, persistence and their role in developing new therapeutic modalities and compounds to optimize clinical outcomes for existing disease states are major areas of interest for the journal. This journal has been accepted for indexing on PubMed Central. The manuscript management system is completely online and includes a very quick and fair peer-review system, which is all easy to use. Visit http:// www.dovepress.com/testimonials.php to read real quotes from published authors.

Submit your manuscript here: https://www.dovepress.com/patient-preference-and-adherence-journal 